\title{
In vitro antimicrobial efficacy of various antiseptic agents
}

\section{applied in peri-implantitis}

\section{Annamária Venkei ${ }^{1}, 2$, Krisztina Ungvári' ${ }^{1}$, Edit Urbán², Kinga Turzó ${ }^{1}$}

\section{- Abstract}

The use of dental implant is an effective way to replace the missing teeth, however the long term successfulness of an implant depends on more factors. ${ }^{1}$

The bacterial adhesion and plaque accumulation on dental implant are one of the most important etiological factor of peri-implant imflammation. ${ }^{2}$ The treatment protocol of periimplantitis consists of debridement of the affected periimplant tissues and decontamination of the implant surfaces. ${ }^{3}$

In our study we investigated the antibacterial effectiveness of different antiseptics, which are widely used in dental practice to find the best gold standard agent among them.

\section{- Background and Aim}

Bacterial colonization and biofilm formation on the implant surface are the major etiological factors of peri-implant infections which can leads to bone resorption and loss of dental implant. Therefore, the reduction of biofilm forming is an essential step for the successful therapy of implantrelated infections.

Several antiseptic agents have been used, however further in vitro experiments are needed to help the dentists to chose the effective therapies to eliminate the microbial biofilm. The aim of the present study was to investigate the antibacterial efficacy of three different antiseptics on Streptococcus mitis in vitro model.

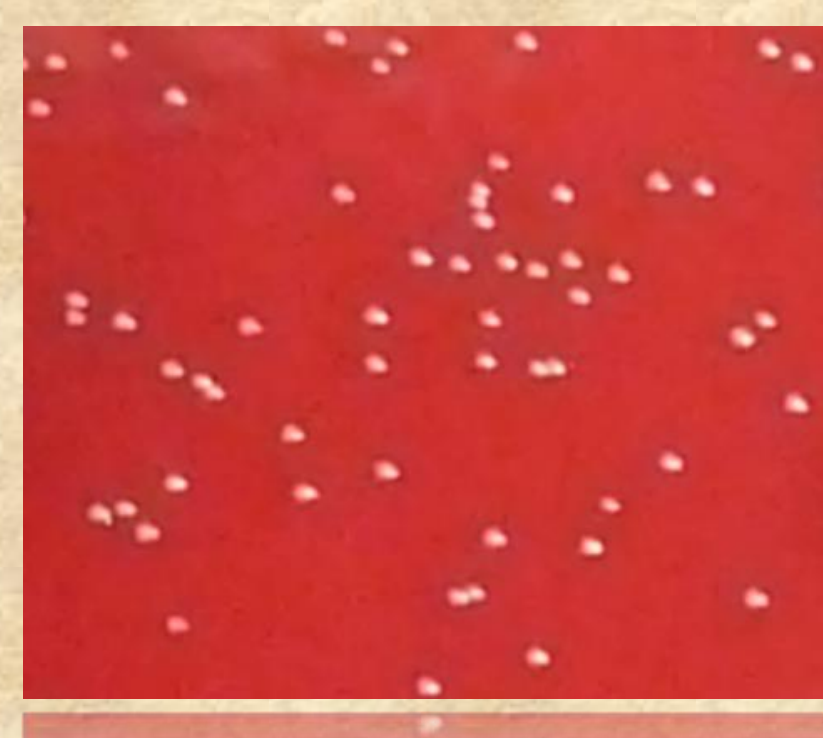

* Figure 1.a-hemolytic isolated colonies of Streptococcus mitis on blood agar

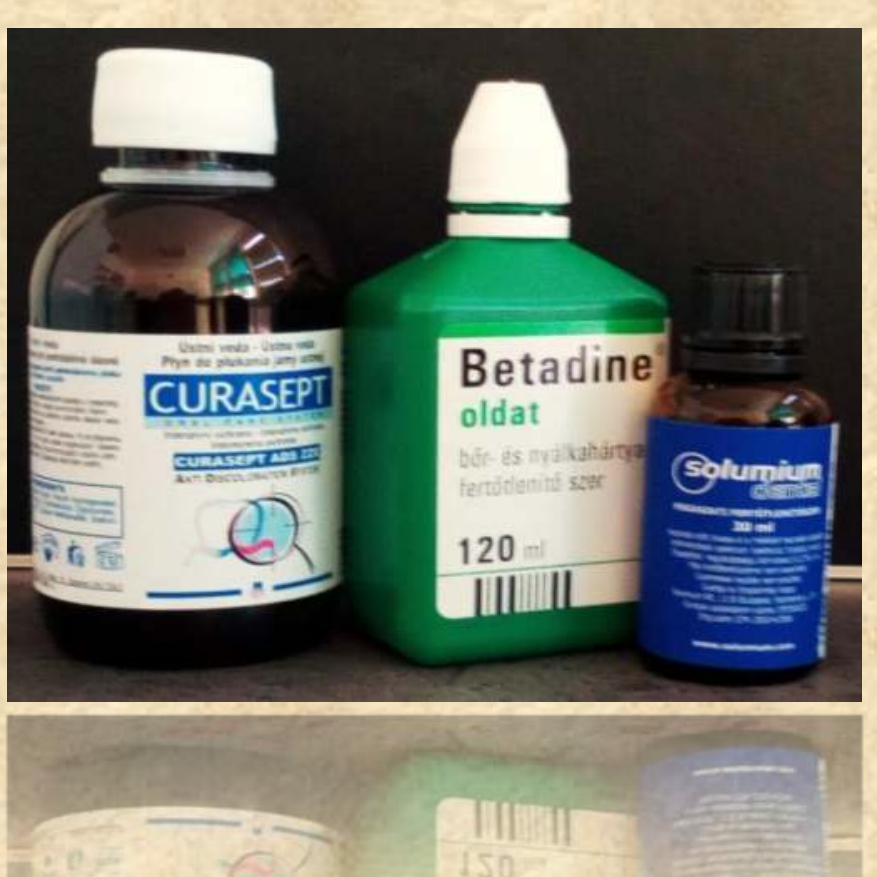

Figure 2. Antiseptics which are used in our study

\section{- Methods and Materials}

Commercially pure (CP4) sand blasted, acid etched titanium sample discs (Denti® System Ltd., Hungary) and Ti discs with polished surface (Dentiß System Ltd., Hungary) were treated with three different antiseptics: clorhexidine (Curasept ADS 220, 0.2\%, Switzerland), povidone-iodine (Betadine, $10 \%$, Switzerland) and chlorine dioxide (Solumium dental, $0.12 \%$, Hungary) for 5 minutes than washed with ultrapure water. Control discs were rinsed with ultrapure water. These disks were incubated with a culture of $S$. mitis, a first colonizer in titanium dental implant associated infections, for 4.5 hours. The clinical isolate of $S$ mitis was identified with MALDI-TOF (matrix assisted laser desorption ionisation- time of flight) mass spectrometer. The antibacterial effect of the antiseptics in each group was represented by the bacterial survival ratio after incubation, determined by MTT assay. ${ }^{4}$
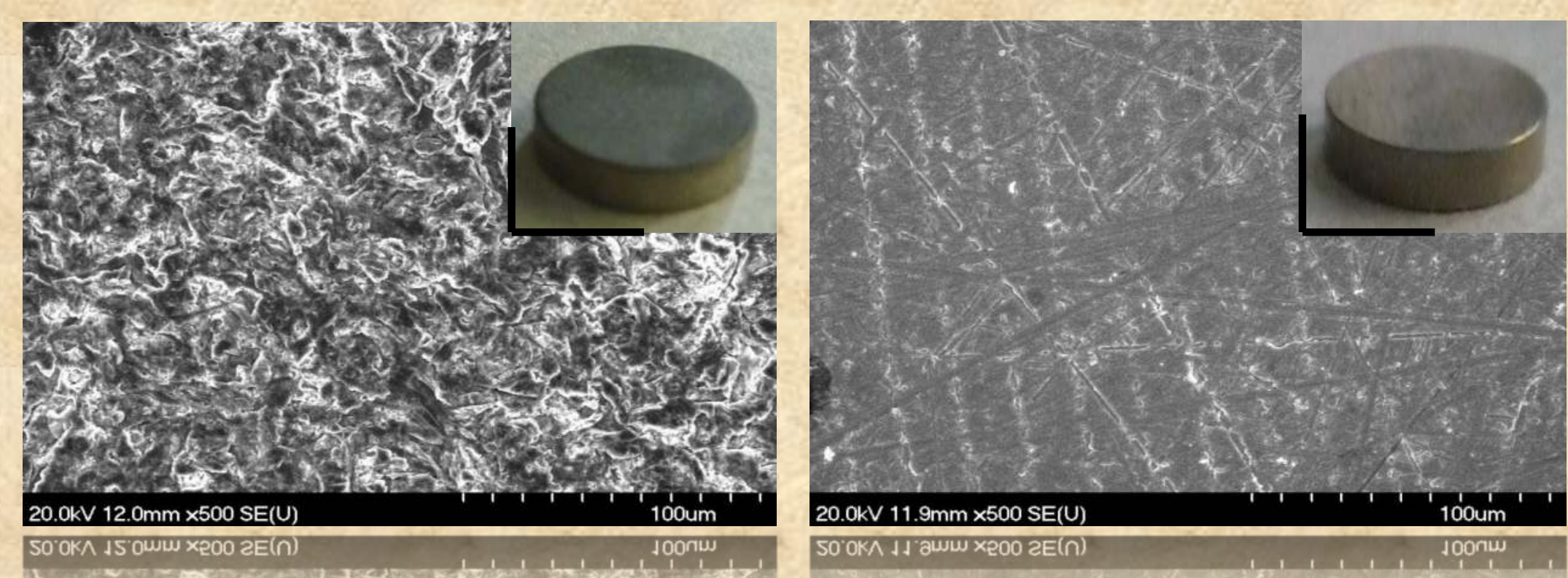

- Figure 3. Surface characteristic of sand blasted, acid etched (A) and polished surface (B) by scanning electron microscope (x10)

\section{Results}

Our results demonstrated that more bacterial cells attached to the surface of the control polished titanium discs than to the control sand blasted and acid etched titanium surfaces. We observed a decreasing tendency on both titanium based surfaces between the untreated control surfaces and the treated samples in the number of attached bacterial cells. According to MTT results the clorhexidine and the chlorine dioxide after washing were the two most effective antiseptics against bacterial cells. We observed the least living bacterial cells on the surfaces of chlorine dioxide treated sand blasted and acid etched samples.

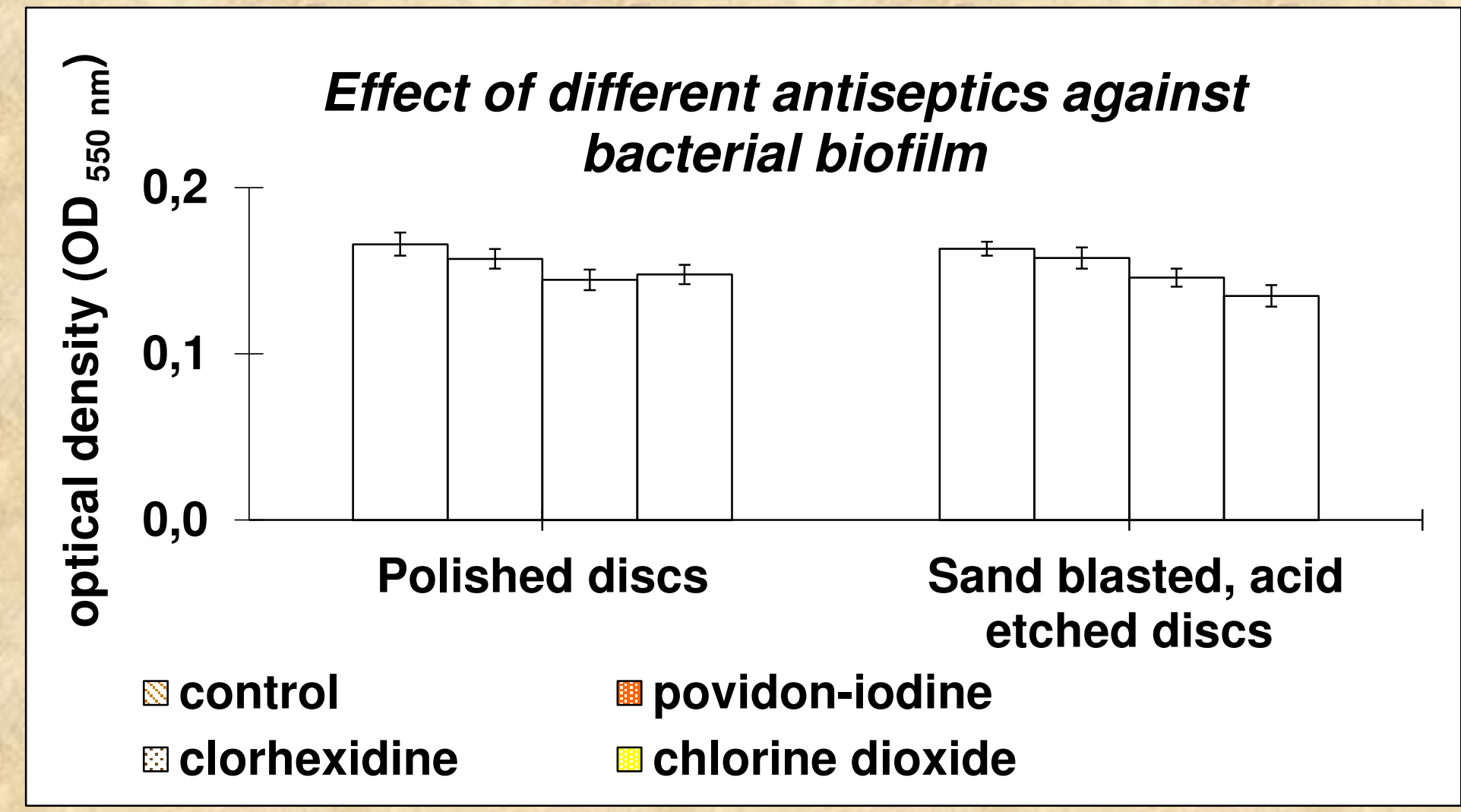

* Figure 4. MTT results

Conclusions

According to our results all antiseptics were effective in the elimination of the biofilm, however the chlorine dioxide showed the most effective antibacterial effect on the surfaces of sand blasted and acid etched sample discs. Therefore, we can conclude that the sand blasted and acid etched titanium implant treated with chlorine dioxide can be an effective choice in the therapy of peri-implant infections.

\section{- References}

1.Tatullo $M$ et al. Bone Inflammation, Bone Infection and Dental Implants Failure: Histological and Cytological Aspects Related to Cement Excess. J Bone Jt Infect. 2017; 2(2): 84-89

2. Lang NP et al. Biological complications with dental implants: Their prevention, diagnosis and treatment. Clin Oral Implants Res. 2000;11(Suppl 1):146-55

3. Smeets $\mathrm{R}$ et al. Definition, etiology, prevention and treatment of periimplantitis - a review. Head Face Med. 2014; 10:34

4. Mosmann T. Rapid colorimetric assay for cellular growth and survival: Application to proliferation and cytotoxicity assays. J Immunol Methods, 1983; 65:55-63.

\section{Acknowledgement}

The present study was supported by the following grant: GINOP-2.3.215-2016-00011 